\title{
Estrategias campesinas en el México revolucionario. El minifundio y la construcción del empoderamiento en los pueblos de Natívitas, (Tlaxcala, 1856-1921)
}

\author{
Evelyne SANCHEZ \\ Benemérita Universidad Autónoma de Puebla, México \\ FRAMESPA-CNRS, Francia \\ s_evelyne@yahoo.com
}

Recepción: 9 de agosto de 2012 / Revisión: 4 de noviembre de 2012

Aceptación: 23 de marzo de 2013 / Publicación: diciembre de 2013

\begin{abstract}
Resumen
En el presente estudio se analiza la recomposición de los poderes locales en el valle de Natívitas (Tlaxcala) entre los años 1856 y 1921, desde un enfoque micro-analítico que privilegia dos ejes originales: la definición de las categorías manejadas por los actores a partir del estudio de su experiencia social y, el examen de su utilización dentro de estrategias en el contexto revolucionario. El texto se compone de dos partes, en las cuales se insertan reflexiones metodológicas y análisis de casos. Primero se expone un balance de los poderes locales en la segunda mitad del siglo XIX y cómo los campesinos comenzaron a construir sus recursos estratégicos frente a los hacendados. En segundo lugar, se analiza cómo la micropropiedad y las categorías vinculadas a ella fueron recursos movilizados exitosamente por los campesinos en las luchas agrarias de la Revolución.
\end{abstract}

Palabras clave: propiedad de la tierra, Revolución mexicana, campesinos, microhistoria, categorías sociales, estrategias, Tlaxcala, México, siglo XIX.

\section{Peasant Strategies in Revolutionary Mexico. Smallholding and Construction of Empowerment in the Villages of Natívitas (Tlaxcala 1856-1921)}

\begin{abstract}
This study intends to analyze the restructuring of the local authorities in the Natívitas Valley, Tlaxcala, from the 1870 's to the 1920 's through a micro-analytical approach that favors two original axes: the definition of the categories handled by actors, which have been taken from the study of their social experience and, at the same time, the analysis of their use within the context of revolutionary strategies. This text is composed of two parts, in which methodological reflections and case studies are presented. The first section of the study presents a balance of the local powers in the second half of the 19th century and a description of how the peasants began to build their strategic resources against the landowners. Then, the text discusses how the smallholdings and their related categories were resources that could be successfully mobilized by the peasants in the agrarian struggles of the Revolution.
\end{abstract}

Key words: Mexican Revolution, Peasants, Microhistory, Social Categories, Strategies, Tlaxcala, Mexico, $19^{\text {th }}$. Century.

Sumario: 1. Introducción. 2. Los hacendados en Natívitas en la segunda mitad del siglo XIX: un poder fragmentado. 3. De la micropropiedad al trabajo de la tierra: la utilización de la categoría de campista. 4. Conclusiones. 5. Referencias bibliográficas. 


\section{INTRODUCCIÓN}

En este artículo se analiza la recomposición de los poderes locales en la región sureste del Estado de Tlaxcala, México, durante la época de la Revolución. Se parte de la reflexión de Buve respecto a la precocidad de la distribución de tierras realizada en el valle de Natívitas en comparación con el resto de la República -debido a la importancia de los movimientos agrarios armados- que demuestra un empoderamiento excepcional por parte de los campesinos de la región. Es este proceso de empoderamiento, concepto que entendemos como la capacidad de los campesinos de construir recursos pertinentes en su relación con los hacendados, lo que ahora se busca elucidar con el apoyo de las herramientas teóricas y metodológicas del microanálisis.

Conviene aclarar los aspectos metodológicos que guiaron este trabajo. Se consideró prioritario apoyarse en los avances historiográficos acerca de las prácticas de poder, es decir sobre la construcción social del poder, entendido como el resultado de una relación. La renovación de la historia social y de la historia política muestra, desde algunos decenios atrás, la confluencia de ambas tendencias historiográficas ${ }^{1}$. Sin duda, este replanteamiento se ha alimentado de los aportes de la microhistoria italiana (especialmente de la obra de Giovanni Levi) y, a través de ésta, de los avances teóricos de la antropología y la sociología sobre el agudo problema en torno al concepto de poder ${ }^{2}$. Desde estos estudios se ha considerado el poder como una relación y no como un atributo del actor, el análisis desplaza su enfoque hacia la calidad de los vínculos en función de variables imprescindibles: la pertinencia de los recursos de los actores en función de sus objetivos, la incertidumbre en que se enmarca la acción social, y otros ${ }^{3}$. También se ha procedido a un cambio de escala: no interesa tanto el actor como su inserción dentro de una configuración de actores. Finalmente, se elaboró una teoría del juego para el análisis de una microsociedad que, mediante los cambios de escalas, permite alcanzar una historia global a partir del microanálisis; o bien, permite una historia total "a ras de suelo" (como escribía Jacques Revel) por medio de la reconstrucción de la multitud de contextos en que se mueven los actores y en interacción con ellos ${ }^{4}$.

Por lo tanto, el presente es un ensayo de historia global basado en el análisis de las "modalidades locales de la gran Historia" en que los actores locales no son víctimas pasivas de eventos que los rebasan, sino por el contrario: son partícipes de los eventos que buscan reinterpretar en su propio beneficio, aprovechándose de cada espacio posible de negociación.

Entre las estrategias, una atrae particularmente nuestra atención: la capacidad de los actores para construir categorías. Los autores de estudios macrosociales no se han

1 Siendo precisos, la historia social de las instituciones y la utilización del análisis de las redes sociales han demostrado la pertinencia del enfoque social para resaltar los mecanismos del ejercicio del poder. Uno de los estudios más importantes sobre la reconstrucción de las prácticas de poder dentro de un marco institucional como espacio de negociación entre la Corona y las élites criollas novohispanas, es el libro recién traducido de BERTRAND, 2011.

2 Sobre la relación entre microhistoria y las ciencias sociales, ver REVEL, 1996.

3 Crozier - Friedberg, 1977; Elias, 1991; Barth, 1981; Rosental, 1996, pp. 141-159.

4 Imízcoz, 2010; Revel, 1989, pp. I-XXXIII. Para un desarrollo más completo de estos conceptos y de la forma en que se articulan unos y otros ver SÁNCHEZ, 2011, pp. 7-21. 
interrogado sobre la pertinencia de las categorías que manejan a priori sin obstar el posible anacronismo o la inadecuación respecto a la realidad observada. Gracias a los aportes de la microhistoria -especialmente en las obras de Cerutti- se ha buscado definir las categorías a partir de la observación de la experiencia social de los actores; de esa manera el microanálisis propone evitar la atribución abusiva, y muchas veces anacrónica, de categorías con las que la realidad que se estudia no encaja ${ }^{5}$. El caso más evidente en nuestro estudio es la incompatibilidad del análisis del poder en los pueblos de Natívitas en términos económicos: el empoderamiento de los pueblos de la región frente al sistema de poder construido por los hacendados no se puede entender únicamente por cuestiones de propiedad como recurso económico sino a través de la relación que la propiedad permite establecer entre los diferentes actores. En consecuencia, se vuelve necesario descubrir las categorías que ayuden a comprender este fenómeno: por ejemplo la de campista -definición que fue evolucionando con el tiempo-, se convirtió en herramienta poderosa para enfrentar a hacendados y a autoridades judiciales.

Para alcanzar dichos objetivos, se presenta enseguida un balance de las relaciones de poder en la segunda mitad del siglo XIX en el que se observa la fragmentación del sistema de poder de los hacendados, a pesar de su búsqueda de control del municipio de Natívitas; después, se planteará la cuestión de los roles de la micropropiedad (o minifundio, los dos términos se mencionan aquí de forma indiferente) y de la categoría de campista en el empoderamiento de los campesinos de esta localidad. Con el fin de centrarnos en esta cuestión, y por la evidente falta de espacio, se han dejado fuera los aspectos vinculados con el tema de los movimientos agraristas en la región, ya bastante atendido, a decir verdad ${ }^{6}$.

\section{LOS HACENDADOS EN NATÍVITAS EN LA SEGUNDA MITAD DEL SIGLO XIX: UN PODER FRAGMENTADO}

Ubicado entre los ríos Zahuapan y Atoyac, el valle de Natívitas tuvo las tierras más fértiles de Tlaxcala. Sus haciendas, cuya extensión era modesta - sólo una rebasaba las mil hectáreas-, producían maíz y trigo y pertenecían en su mayoría a empresarios instalados en la ciudad de Puebla ${ }^{7}$.

Entre los hacendados, a finales del Porfiriato destacan (ver cuadro 1): Ignacio Morales Benítez, cuyas propiedades en Natívitas valían 147,000 pesos, y los hermanos Caso quienes, con cinco haciendas, juntaban 290,000 pesos y 372,000 si agregamos la hacienda de su pariente Blas Reguero y Caso. Junto con ellos, sólo los dueños de las haciendas de Santa Elena y de Mixco aparecen como latifundistas, el resto de propietarios eran rancheros y dueños de propiedad mediana. Se volverá adelante

5 Sobre el importante problema de la identificación de las categorías a partir del análisis de la experiencia social de los actores, ver los textos siguientes: Ponce Leiva - AmAdori, 2008, pp. 15-42; LeVI, 1989; CERUTTI, 1990 y 2012.

6 Buve, 1994; Leal - Menegus, 1987 y 2011.

7 Para una adecuación de las definiciones de la gran y mediana propiedad al contexto regional, ver Ramírez RANCAÑo, 1990, pp. 28-32 y 82-84. 
sobre la dificultad de ubicar su papel en la recomposición de los poderes locales en la Revolución.

Cuadro 1. Haciendas y hacendados de Natívitas en 1905.

\begin{tabular}{|l|l|c|c|c|}
\hline \multirow{2}{*}{$\begin{array}{l}\text { Nombre del dueño de la } \\
\text { finca }\end{array}$} & \multirow{2}{*}{ Nombre de la finca } & \multicolumn{2}{|c|}{ Extensión en } & $\begin{array}{c}\text { Valor fiscal de } \\
\text { la Finca }\end{array}$ \\
\cline { 4 - 5 } & Hectáreas & Acres & \\
\hline Ignacio Morales Benites & Hacienda de Santa Agueda & & & 50000 \\
\hline Ignacio Morales Benites & Hacienda de Dolores & & & 35000 \\
\hline Ignacio Morales Benites & Hacienda Santiago Michac & 513 & 18 & 62000 \\
\hline Bernardo y Alfredo Caso & Hacienda Michac & & & 40000 \\
\hline Bernardo y Alfredo Caso & Hacienda Santa Bárbara & & & 40000 \\
\hline Bernardo y Alfredo Caso & Hacienda Santo Tomás & 596 & 79 & 60000 \\
\hline Bernardo y Alfredo Caso & Hacienda Santa Clara & 575 & 95 & 80000 \\
\hline Bernardo y Alfredo Caso & $\begin{array}{l}\text { Hacienda Santa Ana } \\
\text { Portales }\end{array}$ & 476 & 53 & 70000 \\
\hline Blas Reguero y Caso & Hacienda Los Reyes & 531 & 81 & 82000 \\
\hline Ricardo Carvajal & Hacienda Mixco & 867 & 1 & 54400 \\
\hline Ramón Cervantes & Hacienda Buenavista & & & 8222 \\
\hline Baldomero Rejón & Hacienda Santa Elena & 558 & 5 & 85000 \\
\hline Félix Pérez & Hacienda San Bartola & 1227 & 26 & 20000 \\
\hline Félix Pérez & Hacienda San Jacinto & & & 36000 \\
\hline Juan Pérez & San Miguel Xoxtla & & & 20000 \\
\hline
\end{tabular}

Fuente: Número de haciendas y ranchos que existen en el estado de Tlaxcala, con expresión de los nombres del dueño y nombre de la finca, su extensión en hectáreas, valor fiscal de la finca, sus principales producciones agrícolas, el Municipio y Distrito a que pertenecen. Gobierno del Estado, Tlaxcala, $1905^{8}$.

Los terratenientes no se contentaban con invertir en la tierra como un simple complemento a otras actividades económicas, industriales sobre todo, con el fin de diversificar su patrimonio. Como bien lo ha subrayado Tortolero, tiempo es de revisar la creencia -heredada de Molina Enríquez- según la cual la gran propiedad no rinde: las haciendas se administraban, en el siglo XIX al menos, como un ramo de las actividades productivas que debían rendir beneficios gracias a una serie de inversiones que vislumbraban modernizar la propiedad, su producción y su vinculación con el mercado $^{9}$. Las haciendas ubicadas en el municipio de Natívitas muestran esta voluntad de modernización basada en inversiones que permitían a sus dueños aprovechar al

8 Archivo Histórico del estado de Tlaxcala (en adelante AHET). Sección Justicia y Gobernación, Caja 61, Exp. 3, 16fs.

9 TorTOLERo, 2008. Tortolero expone en esta obra un planteamiento que hizo anteriormente Kourí para valorar y afinar el análisis del proceso de privatización de las tierras comunitarias en el Porfiriato. KouRí, 2002, pp. 69-117. 
máximo su cercanía con la gran ciudad de Puebla y con la vía de ferrocarril interoceánica que comunicaba la región con los mercados más importantes de la república. De hecho, el estado de Tlaxcala tenía la red ferroviaria más densa del país, sólo quedaba a los hacendados financiar la construcción de las vías desde sus propiedades hasta la estación más cercana y justamente una había sido construida en Analco, colonia agrícola de Natívitas creada en el Porfiriato. Según la estimación optimista del presidente municipal de Natívitas, la distancia de las haciendas a la estación variaba de 2 a $4 \mathrm{~km}^{10}$.

Al ferrocarril se añadieron una serie de inversiones para conectar las haciendas de la región con las redes telegráficas y telefónicas ${ }^{11}$. Este recurso resultó muy valioso durante los años de Revolución: cuando los campesinos sublevados ocuparon las haciendas, sus dueños mandaron cantidad de telegramas al gobernador del Estado y a la Federación para obtener su apoyo y pedir el retiro de las tropas agraristas. Con la introducción de la tecnología, las escalas no sólo dependían de la distancia sino también del tiempo y para eso los hacendados disponían de un recurso que los campesinos y los pueblos no detentaban ${ }^{12}$.

Pero esa infraestructura servía también para recibir información y resultados de resoluciones, así nos enteramos, por ejemplo, que la dueña de la hacienda de Segura Michac había solicitado el apoyo de la Comisión Nacional Agraria para detener la distribución de tierras de su hacienda en ejidos para el pueblo de Santa María de Natívitas. Con base en esta intervención, su marido, quien gestionaba la propiedad, propuso a los campesinos firmar contratos de aparcería ${ }^{13}$. De este modo, la agilización de la circulación de las notificaciones oficiales permitía a los hacendados acercarse virtualmente a instancias que les eran favorables para ampliar su margen de maniobra al nivel local y modificar su relación con los campesinos. Con el respaldo de la Comisión se podía retomar, si no el control, por lo menos la iniciativa para redefinir la relación entre pueblo y hacienda, a través de una herramienta acostumbrada: un contrato que mantenía la propiedad en un status quo que no afectaba la economía del

10 Boleta para recoger datos relativos a ferrocarriles foráneos. De propiedad particular. Zacatelco, 6-V1912. AHET, Fondo Revolución-Régimen Obregonista, Sección Justicia y Gobernación, Caja 138, Exp. 8, 4fs. Jacinto Mejía, presidente Municipal de Natívitas, presenta datos relativos a teléfonos de propiedad particular y ferrocarriles foráneos en el distrito de Zaragoza. En 1906, La Antigua República evaluaba la distancia de la hacienda de los Reyes a la estación de Analco en 7,5km.Tlaxcala, 29-VII-1906.

11 Boleta para recoger datos relativos a teléfonos de la propiedad de particulares. Zacatelco 6-V-1912. AHET, Fondo Revolución-Régimen Obregonista, Sección Justicia y Gobernación, Caja 138, Exp. 8, 4fs.

12 En 1916, la viuda de Bernardo Caso se alarmaba porque el telegrama que había enviado al gobernador militar Máximo Rojas parecía no haber llegado a sus manos. Denunciaba en este documento el hecho de que el capitán Miguel Rojas ocupaba con sus tropas sus haciendas de San Antonio y de Santo Tomás, ambas ubicadas en Natívitas, en nombre de Rojas. Reyes pretendía sembrar allí trigo con "los vecinos de los pueblos colindantes". Carta de la viuda e hijos de Bernardo Caso al Gobernador de Tlaxcala. Puebla, 23-XII-1916. AHET, Fondo Revolución Régimen Obregonista, Sección Justicia y Gobernación, caja 207, exp. 36, 9f.

13 En 1921, el presidente municipal de Natívitas, Ricardo Portillo, tuvo que detener la distribución de tierras ejidales tomadas de la hacienda de Michac, propiedad de Natalia Pacheco, después de recibir un telegrama de la Comisión Nacional Agraria para que se "suspendiera inmediatamente la posesión provisional" acordada por el gobernador de Tlaxcala a este pueblo. Telegrama del Secretario General del Gobierno del Estado de Tlaxcala al licenciado Luis Solano Cardoso. Tlaxcala, 27-VI-1921 AHET, Sección Fomento, Serie Agricultura y Ganadería, caja 2, exp. 5. 
hacendado en la medida que era, de todos modos, incapaz de explotar sus tierras en el contexto que se encontraba la región por esos años.

Si las relaciones basadas en intereses mutuos se evidencian con el gobierno del estado, es importante interrogarse sobre los vínculos entre hacendados y autoridades locales de Natívitas, ya que entre sus pueblos se encontraba la mano de obra y las organizaciones comunitarias con las que había que contar para compartir el acceso a los recursos naturales. Como ya se mencionó, las tierras del valle de Natívitas eran especialmente fértiles por encontrarse entre los ríos Zahuapan y Atoyac que se unen en este distrito. La riqueza de la región se refleja en los ingresos municipales, si las cifras que proporciona Alfonso Luis Velasco son correctas: mientras los municipios solían tener cuentas equilibradas entre ingresos y egresos, Natívitas era el municipio que mayores ingresos recibía respecto a sus gastos. Esta situación no dejó a los hacendados poblanos indiferentes y el control de la municipalidad de Natívitas se convirtió en el siglo XIX -quizás antes- en un objetivo constante, alcanzado mediante dos estrategias: la elección de un hacendado como presidente municipal, o bien la elección de un nativo del municipio que actuaba como representante de los intereses de los hacendados.

Cuadro 2. Ingresos y egresos de los municipios del distrito de Zaragoza.

\begin{tabular}{|l|r|r|}
\hline Tesorerías & Ingresos & Egresos \\
\hline Zacatelco & $\$ 1067.86$ & 1067.86 \\
\hline Teolocholco & 223.58 & 223.58 \\
\hline San Pablo del Monte & 295.45 & 281.59 \\
\hline Xicohtencatl & 977.47 & 977.47 \\
\hline Natívitas & 1310.14 & 987.87 \\
\hline Tetlatlahuca & 136.08 & 136.08 \\
\hline Tepeyanco & 171.00 & 171.00 \\
\hline Totales & $\$ 4181.58$ & $\$ 3845.45$ \\
\hline
\end{tabular}

Fuente: Velasco, 1998, p. 85.

Tanto el interés de los hacendados por el poder municipal como sus estrategias son perceptibles en los repetidos conflictos electorales anteriores a la Revolución. Centraremos la atención en los expedientes mejor documentados, los relativos a las elecciones municipales de 1857 y 1872.

En el primer caso se denunciaba la elección de personas que la ley descartaba, especialmente de Gregorio Ábalos, hacendado poblano. Los firmantes de la queja eran habitantes de Natívitas entre los cuales destacaban los Contreras, familia que en los decenios posteriores aparecen como los principales representantes locales de los hacendados ${ }^{14}$. En 1857 la situación política regional era compleja debido a

14 El común de Natívitas solicita al Gobernador de Tlaxcala que anule las elecciones municipales por haberse elegido a personas que la ley excluye. Natívitas, 12-IX-1857. AHET, Justicia Civil, Caja 51, Expediente 37, 14fs. 
la mala recepción que se hizo a la nueva constitución: como se sabe, los conservadores poblanos se sublevaron y varios pueblos tlaxcaltecas les siguieron, aún en varios de ellos fue imposible proceder siquiera a la lectura pública del texto constitucional. En ese mismo año, varios vecinos de Natívitas se organizaron para solicitar la cancelación de la elección dando argumentos para cada cargo: en el caso del presidente municipal, Gregorio Ábalos, tenía "una causa de responsabilidad pendiente por desmanes cometidos en otra época en que sirvió dicho encargo en Natívitas", motivo por el que no podía ser electo y ni siquiera tener voto activo o pasivo; por si fuera poco, no era vecino ni tenía residencia en el pueblo sino en la ciudad de Puebla hasta el punto que Ábalos jvotaba en Puebla!

Dos regidores y un alcalde fueron también objeto de acusaciones, en las que alternan argumentos legales y rumores. Pero eso no fue lo sorprendente del asunto, sino el informe que entregó el colegio electoral del municipio al gobierno del Estado: resultó que Gregorio Ábalos y sus amigos habían sido electos con 18 votos cuando el colegio se componía de 28 ciudadanos y 26 habían asistido al proceso electoral. Como es obvio, ninguna planilla de oposición tuvo la oportunidad de presentarse, de ahí la denuncia presentada después de la elección, única oportunidad de contrarrestar una elección afianzada antes. La oficina del gobernador pareció atender la queja y suspendió la toma de posesión hasta la resolución del conflicto. En ese momento el colegio electoral decidió intervenir y presentar también sus argumentos: desconociendo de entrada las acusaciones de sus contrincantes, plantearon el problema tratando de llamar la atención del poder estatal al subrayar los aspectos políticos en que descansaban los eventos locales. De esta forma, Gregorio Ábalos apareció como el incansable defensor de la causa liberal y constitucional frente a individuos involucrados con el ayuntamiento anterior, opositor declarado de la Constitución de 1857. En cuanto a la residencia del presidente electo, los miembros del colegio electoral mencionaban que

el Sr Ábalos aunque sale de Natívitas varias veces, pero lo hace por sus negocios como lo hacemos todos, mas no porque se ha vecindado en Puebla, pues en Natívitas tiene su casa puesta y en ella su familia ${ }^{15}$.

Mencionar la casa de Ábalos resultó curioso, ya que un evento ocurrido dos años después iba a revelar la falsedad del argumento y la forma en que el presidente municipal amarraba las lealtades en la localidad. En plena guerra de Reforma, las tropas liberales de José María Bocanegra eligieron precisamente la casa de Ábalos para alojarse una noche. Informado enseguida, Ábalos escribía al gobernador una carta en la que solicitaba la exoneración del pago de la contribución del subsidio extraordinario debido a los destrozos que su casa había sufrido y también a los leales servicios rendidos al gobernador ${ }^{16}$. En ambos argumentos se nota cómo el

15 Carta de los electores nombrados de Natívitas al Congreso de Tlaxcala. Natívitas, 15-IX-1857. AHET, Justicia Civil, Caja 51, Expediente 37, 14fs.

16 Carta de Gregorio Avalos al Gobernador. Comunica sobre los daños que sufrió su casa ubicada en Natívitas. Puebla, 10-XI-1859. AHET, Fondo Gobierno, Serie Relaciones Interiores y Exteriores, Caja 11, exp. 114, 3 fs. 
empresario poblano había tendido vínculos personales en la región. En efecto, entre los objetos personales destruidos se encontraban "libros y demás documentos (...) y en estos se contenían deudas a mi favor": si los papeles que conservaban el registro de las actividades de crédito no se encontraban en Puebla era, sin duda, porque involucraban a personas de Natívitas, y entre ellas probablemente aquellas que tanto interés habían demostrado, dos años atrás, en defender la elección de Ábalos como presidente municipal. El crédito era sin duda un recurso poderoso para que los empresarios poblanos dueños de haciendas en Natívitas pudieran hacerse de obligados en la región y encontrar en la localidad a quienes defendieran sus intereses. A estos vínculos tejidos hacia abajo, se agregaban otros tendidos hacia arriba: el desafortunado Ábalos mencionaba el robo unos meses antes de un caballo

en que tuve el alto honor de acompañar en clase de Ayudante al Exmo Señor Gobernador Don Manuel Saldaña en los primeros meses del año pasado, y de ello es fiel testigo VE mismo ${ }^{17}$.

De hecho, hasta la caída de Huerta el gobierno del Estado se mantuvo con el apoyo constante de los dueños de las haciendas tlaxcaltecas, la anécdota que nos reporta la carta del empresario nos enseña una de las formas que podía adoptar esta colaboración en la vida cotidiana mediante lazos personales. En cuanto a la casa, resulta que en 1859 estaba en ruina, con el techo caído, y ubicada en un pueblo que no presentaba el menor interés, por tanto, de tener que pagar el subsidio, Ábalos prefería entregar su propiedad para que el Estado procediera a su enajenación, forma apenas disfrazada de forzar la mano del gobernador. Está claro que en ese momento justificar su residencia en Natívitas ya no formaba parte de sus preocupaciones.

En las elecciones de 1872 el conflicto fue más fuerte -o por lo menos reportado como tal en el expediente judicial-y opuso el pueblo de Santiago Michac al presidente municipal de Natívitas acusado de fraude electoral. Los eventos ocurridos en estas elecciones son importantes para este análisis en la medida que permiten revelar los canales por los que se ejercía el poder de los hacendados y también las resistencias locales que dicho poder encontraba, elemento fundamental para entender cómo los campesinos de la región construyeron a lo largo de los años su capacidad de organización para resistir a los intereses que les resultaban adversos.

Es preciso desglosar el proceso electoral para entender por qué el conflicto se focalizó en el pueblo de Michac. La elección de la autoridad municipal se hacía de forma indirecta: primero los pueblos elegían a su elector, que después los representaría en la elección del presidente municipal. Claro que este proceso fortalecía la unidad de los pueblos como entidades políticas, hecho que se modificó profundamente en los años 1920 con la multiplicación de los partidos políticos. En 1872, los ciudadanos del pueblo de Santiago Michac pudieron optar entre cuatro candidatos: Serapio Vázquez, quien obtuvo el apoyo del pueblo de Santiago Michac ganando la elección con 112 votos; José María de Ocotlán Guevara, quien obtuvo un sólo voto

17 Ibídem. 
y fue presentado en la queja del pueblo como el candidato del hacendado español Enrique Casos, residente en Puebla; Sisto Vázquez, con un solo voto a su favor; y Anastasio Serrano, quien tuvo un poco más de éxito con 12 votos.

En un expediente judicial muy detallado, los diferentes actores y testigos concuerdan sobre las etapas del conflicto mas no en su interpretación. Una vez realizada la votación Enrique Caso solicitó su anulación, pues el resultado era muy desfavorable para su candidato, argumentando que Antonio Ramírez, de la mesa electoral, orientaba los votos. Como nadie prestó atención a su queja,

aquel ocurrió al C. Presidente municipal Francisco Contreras; (...) recogió los papeles pertenecientes a la elección y puso preso a los ciudadanos que formaban la mesa y al C. Antonio Ramírez, permaneciendo por más de una hora encerrado en cuartos de la misma casa del Presidente ${ }^{18}$.

A partir de allí, el pueblo de Santiago Michac quiso demostrar la complicidad entre la autoridad municipal y el hacendado, siendo la primera el instrumento de poder de Caso para controlar a los pueblos de la jurisdicción.

En estos momentos, y como la elección verificada no favoreciera las torcidas miras de los españoles de Natívitas (pueblo cabecera de nuestra municipalidad), pues el impopular y repudiado candidato de estos, José María de Ocotlán Guevara, no hubiese obtenido más de dos votos, mientras que el escogido por el pueblo obtuvo la voluntad general, el Español Enrique Casos, persona enteramente extraña a nuestra elección y sin el menor derecho, se presentó protestando de nulidad a nuestros actos so pretexto de alegar cohecho por parte del C. Antonio Ramírez ${ }^{19}$.

Estos argumentos, presentados primero al gobernador y luego al poder judicial, ameritan una explicación. Según Buve, el hecho de que muchos de los dueños de las haciendas de la región eran extranjeros, españoles en su mayoría, fue uno de los elementos que favorecieron la precocidad de la rebelión campesina que se alimentó de un nacionalismo xenofóbico ${ }^{20}$. Sin embargo, se propone alejarse de una lectura demasiado literal del discurso para adentrarnos en el análisis del proceso de identificación y el uso estratégico de la identidad como parte de un contexto en el cual ésta resulta ser más un instrumento que un fin.

En la cita mencionada arriba, queda claro que el enunciado "las miras torcidas de los españoles de Natívitas" tendría como principal objetivo desacreditar al poder municipal frente a la legitimidad de la expresión popular de los pueblos, en oposición a su cabecera. La forma en que se daba esta expresión nunca fue discutida en el expediente: nadie, ni los actores ni el poder judicial, se tomó la molestia de averiguar si un integrante de la mesa electoral había buscado orientar los votos. ¿Por qué

18 Carta de Antonio Ramírez, Pedro Pérez y Serapio Vázquez, del pueblo de Santiago Michac, al gobernador de Tlaxcala, en el expediente Acusación intentada contra el Presidente Municipal de Natívitas por faltas cometidas en las elecciones primarias verificadas el día 25 de Agosto del año de la fecha. Natívitas, 26VIII-1872. AHET, Justicia civil, Caja 84, Expediente 28, f.2.

19 Ibídem.

20 Buve, 1984, p. 209 y 1994, p. 183. 
lo habrían hecho? En los pueblos las decisiones se tomaban en las asambleas y lo que allí se decidía representaba la voluntad de todos, lo que explica la movilización de todo el pueblo en contra de Caso. Si Ramírez recordó a sus conciudadanos las decisiones tomadas en la asamblea, nadie debía ofenderse salvo un español poco acostumbrado a estos procesos, en especial cuando éstos resultaban ser un contrapoder a sus propias redes clientelares tejidas con la autoridad municipal a espaldas de los pueblos.

La respuesta a la posible pregunta sobre por qué Caso fue a vigilar la elección en Santiago Michac, es sin duda que tardó en darse cuenta de esta debilidad en el sistema de poder que se había creado en la región y que resultaba especialmente sensible en este pueblo ya que, de todos los que dependían de Natívitas, era el que tenía mayor número de ciudadanos, incluso por encima de la propia cabecera (ver cuadro 5). En este contexto, mencionar la nacionalidad de Caso debía servir para fortalecer un argumento legal: nada lo autorizaba a inmiscuirse en el proceso electoral y, de paso, podía servir para sensibilizar a un gobernador liberal.

La reacción de las autoridades no se hizo esperar: el mismo día que se recibió la queja del pueblo de Michac, la oficina del gobernador pidió al comandante militar del Estado mandar una "fuerza armada" a la casa de Francisco Contreras, presidente municipal de Natívitas, para notificarle que al día siguiente tenía que presentarse al juez de primera instancia del distrito y para recuperar los papeles de las elecciones. Esta premura no era nada excepcional, los asuntos electorales solían ser atendidos rápidamente para contener cualquier disturbio; pero también permitía establecer de entrada las responsabilidades: Enrique Caso iba a permanecer al margen de la instrucción del juicio, su intervención ilegal en la elección no se discutiría en ningún momento y, por tanto, toda carga iba a recaer en las autoridades municipales. Al día siguiente, 27 de agosto de 1872, Contreras fue suspendido de sus funciones y liberado con el pago de una fianza, para permitir a la autoridad judicial proceder a la investigación y dictamen del asunto. La lectura de los expedientes judiciales de la época muestra que la liberación bajo fianza era una medida invariable, con la que el sistema judicial parecía recibir una "compensación" por las molestias.

A esta decisión siguió el registro de los testimonios de algunas de las personas involucradas, en la que vale la pena resaltar la ausencia no sólo de Enrique Caso sino también de tres de los candidatos a la elección, Serapio Vázquez fue el único llamado como testigo. Ni siquiera el "candidato del hacendado" se apareció, evidenciando así su papel de eslabón de segundo rango. Las declaraciones de los testigos permiten establecer el perfil de cada uno (cuadro 3). Nos adentramos aquí en el arduo problema de la definición de las categorías que profundizaremos en el apartado sobre la micropropiedad. 
Cuadro 3. Testigos en el conflicto electoral de 1872.

\begin{tabular}{|l|l|l|l|c|l|}
\hline Testigos & $\begin{array}{l}\text { Testimonio } \\
\text { a favor de... }\end{array}$ & Vecino de... & $\begin{array}{l}\text { Actividad en } \\
1872\end{array}$ & Edad & $\begin{array}{l}\text { Actividad en } \\
1865\end{array}$ \\
\hline Antonio Ramírez & Serapio Vázquez & Santiago Michac & Labrador & 43 & Jornalero \\
\hline Pedro Pérez & Serapio Vázquez & Santiago Michac & Campista & 23 & \\
\hline Antonio Hernández & Serapio Vázquez & Santiago Michac & Labrador & 50 & Jornalero \\
\hline Antonio González & Serapio Vázquez & Santiago Michac & Labrador & 30 & \\
\hline Domingo Morales & Serapio Vázquez & Santiago Michac & Labrador & 32 & Comerciante \\
\hline Manuel Nájera & Serapio Vázquez & Santiago Michac & Jornalero & 20 & \\
\hline Felipe Vázquez & Serapio Vázquez & Santiago Michac & Jornalero & 20 & \\
\hline Serapio Vázquez & Serapio Vázquez & Santiago Michac & Preceptor & 25 & \\
\hline Francisco Contreras & Francisco Contreras & Natívitas & Comerciante & 40 & Notario \\
\hline Miguel Solís & Francisco Contreras & Natívitas & Escribiente & 27 & Comerciante \\
\hline José María Contreras & Francisco Contreras & Natívitas & Labrador & 52 & Preceptor \\
\hline
\end{tabular}

Fuentes: Acusación intentada contra el Presidente Municipal de Natívitas por faltas cometidas en las elecciones primarias verificadas el día 25 de agosto de 1872 . Tlaxcala, 27-VIII$1872^{21}$. Padrón y avalúo que demuestra el número de habitantes de todo sexo y edades que se hayan en la municipalidad de Sta. María de Natívitas, con expresión del censo de alma.

Natívitas, 16-II-186522.

El grupo de los labradores parece ampliamente mayoritario, sobre todo del lado de los defensores de la elección de Serapio Vázquez. ¿Se podría concluir, partiendo de estas declaraciones, que los dueños de la propiedad mediana fueron los que representaban al pueblo contra los intereses del principal hacendado de la región quien, en cambio, controlaba la cabecera? Resulta muy arriesgado dar una respuesta definitiva. Comparando la edad con las actividades declaradas, parece que los varones ya maduros tendían a declararse labradores, mientras jornaleros y campistas eran términos reservados a hombres más jóvenes. Cabe aclarar, desde ahora, que el campista era el dueño de un minifundio y que esta categoría supone cierta autonomía de recursos en oposición a los jornaleros.

Obviamente el tamaño de esta muestra no permite arriesgar conclusiones, pero si se cruza este dato con las declaraciones hechas por las mismas personas unos años antes, en el levantamiento del padrón de 1865, la hipótesis podría confirmarse. Lo que sí es posible afirmar con más confianza es lo siguiente: estas categorías eran muy móviles, permeables unas con otras, lo cual podía crear un espacio para que los actores construyeran entonces un recurso. En efecto, lo que se modifica entre 1865 y 1872 no es únicamente la edad de las personas, como es natural, sino también el marco en el que se hizo la declaración. Sin duda, no era lo mismo declarar su actividad en un censo (los fines financieros de éste podían promover cierta modestia) que en un juicio en el que se establecía una relación de fuerza entre las partes en conflicto. En

\footnotetext{
21 AHET, Justicia Civil, Caja 84, Exp. 28, 23 fs.

22 AHET, Sección Gobierno, Serie Censos y Padrones, Caja 42, exp. 26, $77 \mathrm{fs}$.
} 
el pleito, declararse labrador podía funcionar como un recurso para dar más peso al testimonio, fuera cual fuera el estado "objetivo" de las propiedades. Otros documentos tienden a fortalecer esta hipótesis que será crucial para explicar la capacidad de empoderamiento de los campesinos de esta región. En cambio, el oficio de preceptor de Serapio Vázquez nos orienta hacia otra pista: la del recurso cultural, para definirlo de forma bastante amplia.

El juez de primera instancia puso fin al pleito con una decisión salomónica, promulgada el 27 de septiembre, un mes después de que el conflicto se declaró. Sin dictaminar sobre el nudo del problema, se contentó con afirmar que el conjunto de testigos corroboraban la declaración de Contreras: éste levantó efectivamente la mesa electoral, se llevó a sus integrantes y recogió los papeles. Sobre la legalidad de estos hechos, la validez de la votación y el papel del hacendado español en el asunto, el juez no hizo comentario alguno y dio punto final liberando una vez más bajo fianza al presidente municipal.

La elección municipal de 1872 provocó otro conflicto entre un campesino y un administrador de hacienda. Pedro Jácome, vecino de San Miguel del Milagro y peón adeudado de la hacienda de Santa Elena, fue nombrado escrutador para la elección. Lo que muestra que no era necesario estar en una situación de relativa autonomía para desempeñar estas funciones o bien, como demostró Nickel, la deuda no establecía una relación de "esclavitud" de facto o de absoluta dependencia ${ }^{23}$. Cuando Jácome regresó a la hacienda después de tres semanas explicando que, además de desempeñar su función se había enfermado, el administrador lo recibió con insultos y golpes por ser "adicto a la persona del Sr. D. Miguel Lira y Ortega", según el dicho del hermano del peón, quien redactó la carta de queja dirigida al gobernador ${ }^{24}$.

La explicación política que se alude en la carta de queja parecería poco convincente aunque no carece de habilidad: Lira y Ortega había formado parte de los políticos liberales que fomentaron la Constitución de 1857 y la ley de elecciones de Ayuntamientos, y ocupó dos veces el cargo de gobernador del estado de Tlaxcala. Vincular la función de escrutador de Jácome con el célebre gobernante liberal podía resultar provechoso; sin embargo, el tema no reapareció en el expediente, lo que tiende a mostrar que el juez no dio mucho crédito a dicha afirmación. Real o no, la afirmación del vínculo con Lira y Ortega no carece de significados: el peón, lejos de sentirse indefenso, era capaz de percibir que los conflictos políticos fragmentaban las élites, creando al mismo tiempo un espacio de oportunidad para él. Encontramos fortalecido el argumento presentado en el conflicto electoral de 1857: afirmarse liberal en una región donde las élites conservadoras poblanas pretendían la hegemonía, podía resultar una estrategia eficaz para obligar a las élites políticas tlaxcaltecas a tomar sus distancias.

23 Nickel, 1987, pp. 99-127. Recordemos brevemente los argumentos del autor: en las haciendas tlaxcaltecas, las deudas heredadas del padre eran casi inexistentes, una deuda alta era un elemento de prestigio entre los peones porque demostraba la confianza del administrador de la hacienda, la deuda se generaba desde la contratación con un adelanto del salario y también se manejaban para no tener que aumentar el salario, y crear así derechos, cuando éste era insuficiente al mantenimiento de la familia.

24 Acusación intentada contra el Alcalde $1^{\circ}$ de Natívitas y Bruno Quintanilla. Tlaxcala, 19-IX-1872. AHET, Justicia civil, Caja 79, exp. 18, 27fs. 
Nuevamente, además del actuar del administrador, se cuestionó la actitud de las autoridades municipales, pues el alcalde primero de Natívitas, Antonio Chumacero, decidió guardar prisionero a Jácome y cobró cuatro pesos de multa al administrador por los agravios. En este caso, el juez tampoco quiso intervenir tajantemente: si bien reconoció que el administrador de la hacienda era culpable de maltratos y el alcalde de abuso de poder, terminó dictaminando que el primero ya había recibido su castigo con la multa y el segundo había pecado por ignorancia, por lo que quedó libre con una fianza de 50 pesos. Conservemos en mente este caso que, más adelante, nos ayudará a resolver el difícil problema de definir la escurridiza categoría de campista.

Los casos presentados arriba permiten acercarse a la complejidad de las relaciones de poder existentes en la región de Natívitas en vísperas de la Revolución. A pesar del peso que representaban los hacendados poblanos vinculados con el poder municipal, el microanálisis de los conflictos pone de manifiesto la fragmentación de este poder y la capacidad de los campesinos para aprovecharse de esos espacios gracias a diversas estrategias: el aprovechamiento de las divisiones de las élites regionales, la utilización de argumentos a los que la autoridad judicial podía ser sensible -lo que demuestra el uso de recursos cognitivos no desdeñables-, el manejo de categorías conforme a sus intereses y, finalmente, la posibilidad de movilizar la solidaridad del pueblo frente a la voluntad de la autoridad municipal. Estos recursos, utilizados quizás con cierta parsimonia durante los años de la pax porfiriana, hicieron que, apenas estalló la Revolución, los campesinos de esta región ya estuviesen listos para exigir a los hacendados la entrega de sus tierras.

\section{DE LA MICROPROPIEDAD AL TRABAJO DE LA TIERRA: LA UTILIZACIÓN DE LA CATEGORÍA DE CAMPISTA}

Del panorama regional que se ha presentado resaltan dos elementos: por un lado, el poder ejercido en la localidad y en la región por hacendados residentes en Puebla pero vinculados con el poder estatal y municipal; por otro, la temprana reacción organizada de los campesinos vinculada con una estrategia discursiva, posibilitada gracias a recursos culturales que les permitían aumentar su capacidad de negociación con las autoridades. Tiempo es entonces de presentar el problema central de esta investigación: ¿qué empoderó a los campesinos de Natívitas? ¿De qué recursos disponían y cómo los utilizaron dentro de sus estrategias? Y, por fin ¿qué impacto tuvieron esas estrategias y negociaciones en los pueblos? En este apartado se abarca uno de los múltiples aspectos de este empoderamiento: el del minifundio.

Raymond Buve sugiere que la micropropiedad es el elemento que permite entender la cronología peculiar de los procesos agrarios en esta región, ya que ésta permitió dar una base social a los movimientos agraristas de los hermanos Arenas y de Máximo Rojas, éste último tres veces gobernador y comandante militar del Estado. En efecto, mientras la gran mayoría de las distribuciones de tierras se realizaron en México bajo la presidencia de Lázaro Cárdenas (en el periodo postrevolucionario de 1934 a 1940), en la zona sureste del Estado de Tlaxcala, bastión del agrarismo, el 
proceso de distribución -no sólo de solicitud- arrancó desde 1916 y conoció una clara aceleración a partir de 1920.

La distribución de tierras solía operarse en tres etapas: la restitución de tierras (1), que debía apoyarse en la demostración de usurpación por parte de los hacendados, pero como pocos pueblos disponían de la documentación necesaria se decidió recurrir a la dotación de tierras (2) y por último a la ampliación (3 ${ }^{25}$. En los casos de los pueblos de Natívitas la solicitud de ampliación se presentó en $1929^{26}$, y Buve evalúa que en 1917 la extensión de las tierras de dotación ya entregadas a estos pueblos casi alcanzaba las 3700 has $^{27}$. Según el mismo autor, esta precocidad se debió al hecho de que los pueblos tenían un pasado de sublevaciones que era la consecuencia de que la micropropiedad empoderara a los campesinos, sin precisar el origen de estas tierras ${ }^{28}$. En otros términos, los campesinos tenían acceso a un recurso clave que les permitía posicionarse frente a la gran propiedad de forma más autónoma que en otras regiones y por lo tanto obtenían un margen de maniobra mucho más amplio.

La hipótesis es interesante, pero plantea tres problemas que no han sido resueltos todavía en la historiografía. El primero es de orden metodológico: si el minifundio es el elemento clave, eso no indica la forma en que los campesinos, como actores, hicieron uso de él. De no plantear esta pregunta se caería en una visión determinista: quien no posee micropropiedad se somete, quien dispone de ella se subleva con relativo éxito. Si la relación entre minifundio y rebelión no es mecánica, se debe plantear en consecuencia el problema de la definición de los filtros que intervienen aprovechando la fragmentación de los sistemas de normas - para retomar los términos de Rosental, que se inspiraba en Bath-. Encontrar estos filtros lleva necesariamente hacia una historia experimental ${ }^{29}$.

Por si fuera poco, este problema se suma a otros de orden historiográfico. El primero es que la micropropiedad no ha interesado mucho a los historiadores de la Revolución: su atención giró más hacia las haciendas y los pueblos receptores de las tierras ejidales. Este enfoque se ha renovado en los últimos veinte años, en especial bajo el impulso de los estudios de Escobar Ohmstede y de un grupo de investigadores que han analizado la estructura agraria en la región de la Huasteca ${ }^{30}$. Resumiendo, quizás

25 Las dos primeras etapas estaban establecidas en la ley agraria del 6 de enero de 1915 emitida por el gobierno constitucionalista de Venustiano Carranza: los dos primeros artículos de la ley definen los criterios que justifican la restitución de tierras a los pueblos, mientras el tercero plantea la posibilidad de la dotación, en función de las necesidades y no por reclamo a un derecho anterior, de tierras colindantes a los pueblos. El $4^{\circ}$ artículo crea la estructura de la Comisión Nacional Agraria así como de la Comisiones Locales Agrarias para llevar a cabo el proceso de distribución de tierras. La ley del 4 de enero de 1927 sobre dotaciones y restituciones de tierras y aguas precisaba en el $7^{\circ}$ capítulo el tamaño de la parcela que cada individuo podía solicitar, o sea de 2 hasta 9 hectáreas en función de la calidad de la tierra. Con base en esto, se podía proceder a las solicitudes de ampliación. CAso, 1950.

26 Este era por ejemplo el caso de los pueblos de Santiago Michac y de Santa Apolonia Teacalco: Vecinos de Santiago Michac solicitan ampliación de ejidos, Tlaxcala, 29-VI-1929 y Ampliación de ejidos de San Antonio Michac, Santa Apolonia Teacalco, 16-VIII-1929. AHET, Fondo Fomento, Serie Agricultura y Ganadería, Caja 10, Exp. 8, 29 fs y Caja 10, Exp. 27, 9 fs.

27 Buve, 1994, p. 158.

28 Este tema se encuentra especialmente desarrollado en BuvE, 1984.

29 Rosental, 1999.

30 Escobar Ohmstede, 2008 y 2010. 
en exceso, sus conclusiones, cabe resaltar varios puntos: primero que la pequeña y mediana propiedad han sido el resultado de la aplicación de la leyes de Reforma, y más aún de las leyes de colonización y de deslinde de las tierras baldías en los años 1880 y 1890; segundo, que estas tierras, adquiridas a haciendas y sobre todo a partir de los comunales de los pueblos, transitaron por el condueñazgo antes de privatizarse por completo como forma de mantener un tiempo una propiedad y el trabajo colectivos; finalmente, el "condueñazgo" y la propiedad privada fueron utilizados por los pueblos también como refugios para quitar a sus cabeceras la posibilidad de involucrarse en la gestión de sus tierras. Si estos estudios constituyen un modelo interpretativo que renueva la historiografía existente, no se puede aplicar tal cual al caso tlaxcalteca. En efecto, el gobernador Próspero Cahuantzi declaró a la Secretaría de Fomento que no existía ninguna tierra baldía en su Estado, impidiendo la llegada de las empresas de deslinde. Por tanto, el proceso de privatización de las tierras fue diferente y tuvo probablemente una cronología propia que sólo una larga inmersión en el archivo de notarías permitiría precisar. Mientras se realiza este trabajo, debemos contentarnos por ahora con el planteamiento de Buve quien, como buen conocedor de los archivos tlaxcaltecas, presiente que la micropropiedad fue un elemento clave del empoderamiento de los campesinos de Natívitas.

Más aun, si debemos considerar el minifundio por la autonomía que proporciona a sus dueños, tampoco disponemos de información sobre la relación que pudo haber entre éste y la aparcería, que suponía un vínculo de dependencia entre medieros y hacendados ${ }^{31}$. Sin embargo, se verá más adelante, esta relación existía y resultó significativa en los conflictos de la época revolucionaria, pero para poder ubicarla se necesita desplazar la mirada desde la tierra hacia sus dueños y/o trabajadores y prestar atención a las categorías muy peculiares que se manejaban en la región sureste de Tlaxcala, en particular la categoría de campista.

En primera instancia, se debe valorar el peso de la micropropiedad dentro del contexto revolucionario. Las fuentes primarias parecen indicar en esos años un fuerte incremento del dinamismo del mercado de tierras que correspondía a las operaciones de compra-venta de pequeños terrenos entre campesinos de los pueblos cercanos a las haciendas. La tabla 4 presenta la síntesis de estas transacciones basada en 65 documentos de compra-venta de terrenos ubicados en la región entre 1911 y $1921^{32}$. El promedio global del valor de un terreno en 33 pesos es muy representativo del conjunto de la muestra, aunque existen en ella precios que van de 13 a 100 pesos por terreno. La documentación no permite interpretar estas diferencias en función de criterios "objetivos" de las propiedades: hay pocas indicaciones sobre su tamaño (promedio de $2900 \mathrm{~m}^{2}$ obtenido sobre 8 terrenos) y ninguna sobre su ubicación respecto del acceso al agua.

Se pueden tomar en consideración las afirmaciones de Leal y Menegus sobre la pérdida, por parte de los campesinos, de las mejores tierras aunque "habían logrado

31 En la documentación tlaxcalteca, se utilizan los términos de medieros y aparceros como sinónimos.

32 La información sintetizada allí proviene de dos tipos de fuentes: la autorización que daba la Secretaría de Gobernación del Estado de Tlaxcala para validar las actas de compra-venta, estableciendo así un control más allá de la escritura ante notario; los expedientes judiciales del Archivo Judicial del Estado de Tlaxcala, distrito de Zacatelco, de 1900 a 1921. 
conservar los suelos tepetatosos de las laderas de los cerros" ${ }^{\prime 3}$. Sin duda esta afirmación es cierta en términos generales, pero un microanálisis preciso del minifundio permitiría una aproximación más fina del tema y una comparación de la situación de los diferentes pueblos y de las diferentes familias de propietarios dentro de cada pueblo. Por lo tanto, partiendo de la propuesta de Levi sobre las estrategias familiares de los campesinos del norte de Italia, se introdujeron dos criterios cualitativos, uno sobre la tierra en función de su vecindario, otro sobre la calidad de la relación entre vendedor y comprador. El primero permite indicar si la compra se realizaba dentro de una estrategia de ampliación del patrimonio juntando tierras vecinas para facilitar su explotación, mientras el segundo permite detectar formas de solidaridad familiar.

Cuadro 4. Compra-venta de terrenos de 1911 a 1921.

\begin{tabular}{|l|l|l|}
\hline & En pesos & Número de casos \\
\hline Precio promedio de terrenos & 33.43 & 65 \\
\hline Precio promedio de terrenos en caso de parentesco & 32.75 & 8 \\
\hline Precio promedio de terreno + casa en caso de parentesco & 31.80 & 15 \\
\hline
\end{tabular}

El primer criterio indica que obtener la colindancia de varios terrenos de un mismo dueño era excepcional: o pocas oportunidades se presentaban o los compradores no estaban dispuestos a desembolsar una cantidad extra para convencer a los vendedores. Por lo tanto, en los casos en que un jefe de familia tuviera varios terrenos, práctica bastante común como lo muestran los numerosos juicios por intestados, éstos se encontraban separados y no necesariamente en las mismas condiciones respecto a la calidad de la tierra o el acceso al agua.

El criterio de parentesco entre comprador y vendedor está mucho más presente aunque no tan frecuente, particularmente en el caso de venta de un terreno sin construcción. Los vínculos familiares no parecen haber afectado los precios, incluso en casos de venta entre padre e hijo. En cambio, el factor de solidaridad parece haber estado presente en la compra-venta de terrenos con casa para permitir la instalación de parientes cercanos.

Estos datos tienden a mostrar que las pequeñas propiedades privadas, o minifundios, eran para las familias campesinas un recurso importante en su vida cotidiana, lo que no implica que fuera necesariamente un elemento de conflicto con la estructura agraria. Al contrario, en esta región donde existían haciendas poco extensas, de cultivos especializados e intensivos, pocos peones eran acasillados. Esto significa que la mayoría de la mano de obra de las haciendas era de jornaleros que residían en los pueblos vecinos, contratados para la temporada de cosecha. En este contexto, estos peones necesitaban el microfundio para dar estabilidad a sus ingresos y por eso micro y macrofundio se complementaban.

33 Leal- Menegus, 2011, p. 75. 
Para entender cómo el minifundio resultó convertirse en un recurso que permitió la lucha temprana de los campesinos para obtener tierras de las haciendas, se debe desplazar la mirada desde la tierra hacia el estatus de sus dueños, analizando una categoría muy propia del valle de Natívitas: la de campista ${ }^{34}$; o preguntarse, en otros términos, ¿cómo los campesinos consiguieron hacer de la micropropiedad un recurso para sus conflictos con los hacendados de Natívitas? ¿De qué modo intervino la categoría de campista?

Para responder a estas preguntas, se dispone de dos tipos de fuentes: los padrones que ofrecen información estadística y las declaraciones en el marco de un conflicto. En el primer caso, las categorías podían adaptarse a las declaraciones de los campesinos (padrones de 1865 y de 1912) o bien ser impuestas y simplificadas en exceso - para los fines de este estudio- por la Secretaría de Fomento con el objetivo de establecer un padrón general de la población del país (establecido por Peñafiel en 1900). Las declaraciones, especialmente en el marco de un pleito judicial, permiten cambiar de escala para comprobar la utilización de la categoría de campista en el marco de una estrategia y dentro de la trayectoria de un actor.

Cuadro 5. Padrón de ciudadanos de 1912.

\begin{tabular}{|l|c|c|c|c|c|c|c|c|}
\hline \multicolumn{1}{|c|}{ Pueblos } & $\begin{array}{c}\text { Núm. } \\
\text { Ciudadanos }\end{array}$ & $\begin{array}{c}\text { Núm. } \\
\text { Profesiones }\end{array}$ & $\begin{array}{c}\% \\
\text { campista }\end{array}$ & $\begin{array}{c}\% \\
\text { jornalero }\end{array}$ & $\begin{array}{c}\% \\
\text { albañil }\end{array}$ & $\begin{array}{c}\% \\
\text { comerciante }\end{array}$ & $\begin{array}{c}\% \\
\text { artesano }\end{array}$ & $\begin{array}{c}\% \\
\text { saben } \\
\text { leer }\end{array}$ \\
\hline $\begin{array}{l}\text { Sta. María de } \\
\text { Natívitas }\end{array}$ & 175 & 17 & 29.14 & 17.71 & 12.57 & 10.86 & 27.43 & 68 \\
\hline $\begin{array}{l}\text { Sta. Apolonia } \\
\text { Teacalco }\end{array}$ & 181 & 5 & 96.13 & 0 & 1.66 & 1.1 & 1.1 & 67 \\
\hline $\begin{array}{l}\text { San Vicente } \\
\text { Xiloxochitla }\end{array}$ & 118 & 5 & 91.52 & 0 & 0 & 2.54 & 1.7 & 50 \\
\hline $\begin{array}{l}\text { San Miguel } \\
\text { del Milagro }\end{array}$ & 109 & 7 & 71.56 & 6.42 & 6.42 & 0 & 11 & 49 \\
\hline $\begin{array}{l}\text { San Rafael } \\
\text { Tenanyecac }\end{array}$ & 90 & 6 & 86.66 & 0 & 1.11 & 3.33 & 8.88 & 51 \\
\hline $\begin{array}{l}\text { San Miguel } \\
\text { Xochitecatitla }\end{array}$ & 149 & 3 & 85.91 & 0 & 13.42 & 0.67 & 0 & 70 \\
\hline
\end{tabular}

34 El tamaño muy reducido del minifundio, de $2900 \mathrm{~m}^{2}$ en promedio por terreno, significa que debemos ser cuidadosos a la hora de mencionar la propiedad mediana. No es posible validar la propuesta de M. Ramírez Rancaño de definirla como las propiedades "cuya superficie oscila entre las 200 y las 1000 hectáreas" pero tampoco confundirla con los ranchos. En la región que interesa ahora, estos criterios corresponden a las haciendas. R. Buve fue más cuidadoso al indicar la dificultad de delimitar al grupo de propietarios medianos, en especial porque en la Revolución los campesinos tendían a tratar de la misma forma a cualquiera que tuviera cierta cantidad de tierras, fuera hacendado o no. Esta situación se explica sin duda por la dificultad que tenían los campistas de aumentar sus propiedades mediante la compra de terrenos vecinos: cualquiera que tuviera la oportunidad de apropiarse de tierras, aunque sólo tuviera una superficie de unas cuantas hectáreas, podía aparecer como un privilegiado y su propiedad ser objeto de codicias. El mismo Buve juzga, sin proceder a un cálculo sistemático, que la mayoría de los jefes de familia de los pueblos de Natívitas o bien no poseían tierras, o bien tenían antes de la Revolución la propiedad de unas superficies que iban de 0.1 a 1.5 hectáreas. Por lo tanto, propone que se considere como de propiedad mediana las tierras mayores a estas, propuesta que nuestros cálculos validan. Ramírez RancaÑo, 1990, p. 82; Buve, 1994, p. 154. 


\begin{tabular}{|l|c|c|c|c|c|c|c|c|}
\hline $\begin{array}{l}\text { Santiago } \\
\text { Michac }\end{array}$ & 209 & 8 & 93.3 & 1 & 0.5 & 0.5 & 1.4 & 48 \\
\hline $\begin{array}{l}\text { Sto. Tomás } \\
\text { Concordia }\end{array}$ & 80 & 2 & 99 & 0 & 0 & 0 & 1 & 40 \\
\hline $\begin{array}{l}\text { San José } \\
\text { Atoyatenco }\end{array}$ & 78 & 6 & 86 & 0 & 1.3 & 0 & 5.1 & 82 \\
\hline
\end{tabular}

Fuente: Padrón que manifiesta el número de ciudadanos existentes en el Municipio de Natívitas. Natívitas, 31-V-1912 ${ }^{35}$.

El padrón de ciudadanos de 1912 (cuadro 5), aplicado únicamente a varones mayores de edad, presenta resultados muy radicales respecto a las actividades declaradas: los jornaleros se encuentran casi todos en la cabecera, y aun allí representan menos de la quinta parte de los hombres. Su presencia en San Miguel del Milagro, débil pero significativa considerando su ausencia en los otros pueblos, no debe causar sorpresa ya que era el pueblo que más carecía de tierras. En cambio, los campistas representan casi la totalidad de los hombres, los demás se reparten en otras pocas profesiones demostrando, si fuera necesario, el profundo anclaje campesino de estos pueblos. Es de notar que la categoría de peón no aparece en el documento a pesar de que el peonaje fue prohibido hasta septiembre de 1914. Entonces, ¿de dónde obtenían las haciendas su mano de obra?

La cuestión se hace más aguda si comparamos estos resultados con los del censo de 1865. En este documento sólo aparecen tres categorías en relación con el trabajo del campo y la propiedad: jornaleros, campistas y labradores. Es importante subrayar varios aspectos. Primero, la relación jornaleros-campistas es inversa a la de 1912, lo cual valida la idea de que, si bien había peones acasillados o calpaneros que vivían en las haciendas, la mayoría de la mano de obra se encontraba en los pueblos vecinos. Segundo, estas categorías no sólo se relacionan con el tipo de trabajo realizado sino también con la propiedad o la ausencia de ésta, pues el campista era dueño de su lote mientras el jornalero trabajaba una tierra ajena. La diferencia es esencial para entender la intencionalidad de los actores al momento de declarar: el censo era un documento base que debía servir a la elaboración de una nueva repartición de la fiscalidad, en particular del impuesto predial ${ }^{36}$. Así que el objetivo de los campesinos en 1865 no era demostrar su autonomía respecto de la gran propiedad sino simplemente evadir impuestos. La comparación de la producción agrícola entre pueblos y haciendas fortalece esta hipótesis, ya que la capacidad productiva de los pueblos no era nada despreciable y ésta descansaba necesariamente en tierras, aunque ignoramos si eran comunitarias o privadas, y en la fuerza laboral. Los únicos que manifestaron el deseo de demostrar autonomía fueron los de Santa Apolonia Teacalco con sus 32 campistas,

35 AHET, Revolución - Régimen obregonista, Justicia y Gobernación, Caja 134, Expediente 73, $217 \mathrm{f}$.

36 Según el estudio de Marichal, la innovación más significativa del gobierno centralista en materia de Hacienda pública fue la creación de impuestos directos sobre la propiedad: el impuesto de dos al millar sobre fincas urbanas y de tres al millar sobre fincas rústicas. Ver MARICHAL, 1994, pp. 101-190. 
pero - como se dijo antes- el pueblo se encontraba en una situación muy peculiar, no en relación con las haciendas sino con su cabecera ${ }^{37}$.

Cuadro 6. Mano de obra y producción en 1865.

\begin{tabular}{|c|c|c|c|c|c|c|c|c|c|c|}
\hline \multirow{2}{*}{$\begin{array}{l}\text { Pueblos, } \\
\text { barrios y } \\
\text { haciendas }\end{array}$} & \multirow[t]{2}{*}{ Jornaleros } & \multirow[t]{2}{*}{ Campistas } & \multirow[t]{2}{*}{ Labradores } & \multicolumn{2}{|c|}{\begin{tabular}{|c|} 
Producción \\
(cargas)
\end{tabular}} & \multicolumn{5}{|c|}{ Ganado (cabezas) } \\
\hline & & & & Maíz & Trigo & Vacuno & Lanar & Caballar & Burros & Cerdos \\
\hline $\begin{array}{l}\text { Total } \\
\text { (núm./\%) }\end{array}$ & $745 / 73.76$ & $105 / 10.40$ & $19 / 1.88$ & 14219 & 4525 & 1599 & 1275 & 482 & 276 & 967 \\
\hline $\begin{array}{l}\text { Santa María } \\
\text { Natívitas }\end{array}$ & 24 & 5 & 5 & 559 & 44 & 13 & 0 & 75 & 21 & 93 \\
\hline $\begin{array}{l}\text { Barrio de San } \\
\text { Juan }\end{array}$ & 12 & & & 10 & 0 & 2 & 0 & 0 & 16 & 11 \\
\hline $\begin{array}{l}\text { Barrio de } \\
\text { Capula } \\
\end{array}$ & 28 & 8 & 2 & 114 & 0 & 45 & 0 & 17 & 12 & 48 \\
\hline $\begin{array}{l}\text { Pueblo de San } \\
\text { Rafael }\end{array}$ & 80 & 8 & & 111 & 0 & 69 & 18 & 4 & 73 & 91 \\
\hline $\begin{array}{l}\text { Barrio de } \\
\text { Jesús } \\
\end{array}$ & 19 & 1 & & 61 & 0 & 22 & 0 & 0 & 9 & 28 \\
\hline $\begin{array}{l}\text { Pueblo } \\
\text { Santuario San } \\
\text { Miguel }\end{array}$ & 69 & 5 & & 89 & 0 & 45 & 48 & 4 & 12 & 47 \\
\hline $\begin{array}{l}\text { Pueblo de } \\
\text { San Miguel } \\
\text { Xochitecatitla }\end{array}$ & 60 & 15 & & 294 & 9 & 87 & 0 & 14 & 40 & 230 \\
\hline $\begin{array}{l}\text { Pueblo } \\
\text { (barrio) } \\
\text { de Santa } \\
\text { Apolonia* }\end{array}$ & 77 & 32 & & 404 & 271 & 114 & 714 & 48 & 46 & 156 \\
\hline $\begin{array}{l}\text { Pueblo de } \\
\text { Santiago } \\
\text { Michac }\end{array}$ & 117 & 13 & & 146 & 48 & 82 & 0 & 15 & 43 & 59 \\
\hline $\begin{array}{l}\text { Pueblo de San } \\
\text { Vicente }\end{array}$ & 33 & & & 74 & 0 & 40 & 91 & 2 & 9 & 18 \\
\hline $\begin{array}{l}\text { Hacienda de } \\
\text { Santa Clara } \\
\end{array}$ & 36 & & 1 & 1100 & 400 & 120 & 0 & 71 & 0 & 0 \\
\hline $\begin{array}{l}\text { Hacienda de } \\
\text { Mixco }\end{array}$ & 6 & & & 1200 & 500 & 0 & 70 & 18 & 4 & 0 \\
\hline $\begin{array}{l}\text { Hacienda del } \\
\text { Rosario }\end{array}$ & 5 & 4 & 1 & 500 & 0 & 50 & 150 & 14 & 0 & 0 \\
\hline $\begin{array}{l}\text { Hacienda de } \\
\text { los Reyes }\end{array}$ & 47 & 3 & 3 & 1000 & 0 & 200 & 210 & 47 & 28 & 15 \\
\hline $\begin{array}{l}\text { Pueblo de } \\
\text { Santo Tomás }\end{array}$ & 34 & & & 3 & 0 & 15 & 0 & 0 & 0 & 1 \\
\hline $\begin{array}{l}\text { Hacienda de } \\
\text { Santa Agueda }\end{array}$ & 13 & & & 800 & 400 & 67 & 70 & 14 & 16 & 16 \\
\hline
\end{tabular}

37 SÁNCHEZ, 2012, pp. 6-14. 


\begin{tabular}{|c|c|c|c|c|c|c|c|c|c|c|}
\hline $\begin{array}{l}\text { Hacienda de } \\
\text { Santo Tomás }\end{array}$ & 16 & & & 800 & 400 & 80 & 100 & 28 & 0 & 0 \\
\hline $\begin{array}{l}\text { Hacienda } \\
\text { de Santiago } \\
\text { Michac }\end{array}$ & 10 & 1 & & 1500 & 400 & 150 & 200 & 70 & 0 & 60 \\
\hline $\begin{array}{l}\text { Hacienda de } \\
\text { Sta. Bárbara }\end{array}$ & 10 & 1 & & 600 & 200 & 60 & 0 & 18 & 19 & 0 \\
\hline $\begin{array}{l}\text { Hacienda de } \\
\text { Dolores }\end{array}$ & 4 & & 3 & 600 & 500 & 16 & 0 & 20 & 0 & 0 \\
\hline $\begin{array}{l}\text { Barrio de } \\
\text { Tlacuitlapa }\end{array}$ & 25 & 6 & & & & & & & & \\
\hline $\begin{array}{l}\text { Hacienda de } \\
\text { Sta. Elena }\end{array}$ & 5 & 3 & 1 & 1400 & 500 & 120 & 0 & 77 & 0 & 0 \\
\hline $\begin{array}{l}\text { Pueblo de Sta. } \\
\text { Elenita }\end{array}$ & 13 & & & & & & & & & \\
\hline $\begin{array}{l}\text { Hacienda de } \\
\text { San Antonio } \\
\text { Michac } \\
\end{array}$ & 2 & & 1 & 200 & 150 & 72 & 0 & 25 & 12 & 31 \\
\hline $\begin{array}{l}\text { Hacienda de } \\
\text { San Rafael** }\end{array}$ & & & & 700 & 200 & 70 & 70 & 16 & 11 & 27 \\
\hline $\begin{array}{l}\text { Hacienda } \\
\text { Sta. Ana } \\
\text { Portales** }\end{array}$ & & & & 2000 & 500 & 100 & 14 & 45 & 15 & 40 \\
\hline
\end{tabular}

Fuente: Padrón y avalúo que demuestra el número de habitantes de todo sexo y edades que se hayan en la municipalidad de Sta María de Natívitas, con expresión del censo de alma. Natívitas, 16-II-1865

* Santa Apolonia aparece en el censo como pueblo y en la evaluación de las producciones como barrio.

**Haciendas que no se mencionan en el censo de población.

Las fuentes estadísticas presentan entonces pistas interesantes que ameritan ser desarrolladas y validadas con análisis de casos. En efecto, si bien es sabido que los censos presentan datos poco fiables debido a sus objetivos financieros, la comparación de estos documentos muestra que el hecho de esconderse para evitar el registro no era ni el único recurso ni el más sutil del que disponían los campesinos. Jugar con las categorías les permitía afirmar su actividad laboral con la tierra escondiendo su relación con la propiedad: se negaba cuando el impuesto predial amenazaba, se afirmaba cuando las reivindicaciones agraristas empezaban a dibujarse en la región y cuando la afirmación de la autonomía respecto a los hacendados representaba un acto revolucionario en sí.

Profundizando un poco, parece que el término de campista tampoco depende completamente de la cuestión de la propiedad. Se sabe que, frente al agrarismo fuertemente anclado en los pueblos de Natívitas, los hacendados intentaron dividir a los campesinos oponiendo los intereses de los agraristas con los de los medieros,

38 AHET, Sección Gobierno, Serie Censos y Padrones, caja 42, exp. 26, $77 \mathrm{fs}$. 
muchas veces miembros de las mismas familias ${ }^{39}$. La estrategia no carecía de lógica: para que el contrato entre medieros y hacendados se cumpliera, se necesitaba respetar la propiedad del último, lo que los campistas, y los que carecían por completo de tierras, no podían aceptar. Además, las tierras rentadas eran precisamente las que los hacendados no podían explotar por cuenta propia, las mismas que después se solicitarían prioritariamente para su distribución. Frente a este intento, la sobreutilización del término de campista por parte de los campesinos muy bien se podría interpretar como una estrategia contraria: tanto medieros como dueños de la pequeña propiedad se declaraban campistas, subrayando de esta forma que lo que les definía no era la propiedad de la tierra sino el hecho de trabajarla para su propio provecho, al contrario del jornalero que sólo vendía su fuerza de trabajo. En un momento en que se estaba organizando el tema agrarista "la tierra es de quien la trabaja", insistir en el trabajo y negar la propiedad en la definición del campesino ciertamente no era casual.

En este ambiente, el éxito del líder agrarista Domingo Arenas se vuelve más comprensible: no era un hombre providencial que intervino desde fuera para organizar a los campesinos, sino que encontró en esta zona las condiciones necesarias para que su movimiento obtuviera el respaldo necesario por parte de la población.

El análisis de casos a partir de fuentes judiciales permite ver que la construcción de este recurso se hizo varios decenios antes de la Revolución. Se retoma como ejemplo el caso ya mencionado de las elecciones de 1872 y del peón endeudado de la hacienda de Santa Elena, Pedro Jácome ${ }^{40}$. Para resolver la situación judicial de los dos acusados -el administrador de la hacienda y el alcalde de Natívitas- se presentaron al juez testigos a favor tanto de los acusados y como del denunciante. Éste último no era Pedro Jácome sino su hermano Gregorio, quien se encargó de presentar el asunto al juez y al gobernador. Las dos personas que representaban la autoridad en la hacienda, el mayordomo y el capitán, declararon ser campistas (ambos eran originarios de la región -el primero de San Martin Texmelucan y el segundo de San Rafael Tenanyecac- y por lo tanto manejaban también estos términos). Los tres peones que comparecieron para testificar los malos tratos formaban parte de la misma cuadrilla que Jácome y fueron arrestados al mismo tiempo que él. Los tres, originarios de Natívitas, de los barrios de Capula y la Trinidad, declararon ser jornaleros mientras Pedro Jácome era presentado por su hermano como peón endeudado. Gregorio Jácome, se identificaba como un campista de San Miguel del Milagro.

La descripción de los hechos casi habla por sí misma. Si se ordena de forma creciente respecto a la autoridad y autonomía pretendida de cada quien, en la base de

39 Mencionamos más arriba el caso de la hacienda de Michac en 1921. Ver nota 12. Raymond Buve, quien pudo consultar el archivo del RAN de Tlaxcala (no disponible por ahora debido a su digitalización en el Archivo General Agrario), rescata esta misma estrategia aplicada por la familia Kennedy a los campesinos de San José Atoyatenco y de Tepetitla. Buve, 1994, p. 162. La lista de medieros de Santa Apolonia Tealcalco en 1916 permite ver que los individuos que se involucraban en estos contratos pertenecían a las mismas familias que lideraban el pueblo y exigían sus reivindicaciones agrarias: los Portillo, Apanecatl, Picil, Lara y Sanpedro. Cuenta de los medieros con la besana del carril que pasa por Natívitas. Natívitas, 30-X-1916. AHET, Fondo Revolución - Régimen Obregonista, Sección Justicia y Gobierno, Caja 190, exp. 20, 8f.

40 Acusación intentada contra el Alcalde $1^{\circ}$ de Natívitas y Bruno Quintanilla. Tlaxcala, 19-IX-1872. AHET, Sección Justicia, Serie Civil, Caja 79, exp. 18, 27 fs. 
la jerarquía social aparece el peón, víctima de los maltratos denunciados a pesar de que su designación como escrutador en las elecciones municipales muestra que no carecía completamente de recursos; luego se encuentran sus compañeros de cuadrilla y finalmente los campistas. Ciertamente, no puede ser casualidad que la persona que llevó todo el asunto a las autoridades se presentara como tal, a pesar de que el pueblo de San Miguel era el que menos tierras poseía, pues de esta manera demostraba su autonomía frente a los empleados de la hacienda y se ponía en el mismo plano que ellos. Como se vio más arriba, si campista era una categoría que podía ser utilizada estratégicamente dentro de un conflicto, declararse peón o labrador podía servir para los mismos fines. Como es lógico, en el contexto de la Revolución, el término de campista resultó ser el más adecuado.

Sin duda este juego sólo era posible debido a la permeabilidad o poca nitidez de las categorías, como lo demuestran cantidades de casos. En un pleito de 1870 por robo en una hacienda se encuentran declaraciones contradictorias: Calisto Ávila se presentó de "ejercicio campista, natural de San Luis Apizaco y vecino actualmente de la Hacienda de San Antonio Michac" donde era velador; el mayordomo se declaraba "labrador"; Eusebio Ávila "campista" y "vecino actualmente de la hacienda de San Antonio Michac"; Matías Ramírez "jornalero, natural del pueblo de Santiago Michac y vecino actualmente de la Hacienda de San Antonio Michac"41. Es decir, un campista podía tener su residencia en la hacienda, como un acasillado, mientras un jornalero podía residir en un pueblo. Lo que resalta de estas situaciones confusas es la utilización por parte de los campesinos de las categorías dentro de un contexto bien definido en el que buscaban defender sus intereses. Esto explica la aparente contradicción de los censos donde la evolución radical que se observa entre 1865 y 1912 no refleja un cambio drástico en la estratificación social sino un profundo cambio en las relaciones de poder y la defensa de intereses diferentes, frente a la fiscalidad en un primer tiempo, frente a la gran propiedad en un segundo momento.

\section{CONCLUSIONES}

Este estudio de caso propone la capacidad de generar conocimiento -tal como lo plantea el microanálisis- como eje de renovación historiográfica sobre la Revolución Mexicana. De este trabajo se pueden obtener dos conclusiones principales: la necesidad de analizar la construcción de los recursos de los actores en una cronología ampliada y la pertinencia de la reconstrucción de categorías tal como las definían y las utilizaban los mismos actores.

El análisis de la configuración de los poderes en la región de Natívitas en la segunda mitad del siglo XIX muestra que los campesinos encontraron la forma de aprovechar las fragmentaciones causadas por las luchas políticas entre las élites. $\mathrm{Si}$ bien los hacendados buscaban alianzas con las autoridades de la zona, con las que

41 En averiguación a los autores del robo que se perpetró en la hacienda de San Antonio Michac practicado por el juzgado $1^{\circ}$ de Natívitas. Natívitas, 25-V-1870. AHET, Sección Justicia, Serie Civil, Caja 77, exp. $34,12 \mathrm{fs}$. 
compartían un mismo modelo de progreso e intereses económicos, no formaban un bloque monolítico. Las luchas entre grupos liberales y conservadores que, como vimos, se estructuraban mediante vínculos personales, no sólo dividieron a las élites sino que dieron a los campesinos la oportunidad de aprovechar estas escisiones a la hora de pedir apoyo a las autoridades, fueran del poder ejecutivo o judicial. El caso del peón endeudado, quien proclamaba su vínculo con el líder liberal tlaxcalteca, muestra cómo los conflictos partidistas podían permear los diferentes estratos de la sociedad y de qué forma podían ser aprovechados. Las elecciones fueron momentos en que los conflictos de poder se hicieron más visibles y allí es donde podemos observar la construcción de recursos peculiares por parte de los campesinos, en especial la utilización de categorías en sus declaraciones para dar más peso a sus testimonios frente a los jueces. Como era de esperar en una sociedad campesina, estas categorías eran relativas a la propiedad y al trabajo de la tierra.

Si bien este recurso era utilizado de forma puntual bajo el Porfiriato, se volvió sistemático en tiempos de revolución hasta el punto de entrar en un "juego de estrategias" con los hacendados. Mientras éstos buscaban dividir a los campesinos proponiendo algunos contratos de aparcería para afianzar su propiedad, la categoría de campista - hasta ahora descuidada por la historiografía- se transformó para servir a la reivindicación de "la tierra es de quien la trabaja", tejiendo así un vínculo de solidaridad precisamente donde los terratenientes pretendían destruirlo. Por lo tanto, cada categoría debe ser analizada no sólo dentro de su contexto social, económico y político sino también en función de su relación con las otras categorías para entender cómo su definición se modificó, desde una referencia a la propiedad hacia el uso a beneficio propio o posesión.

A partir de este ensayo, quedan pendientes varios problemas que el estado actual de la historiografía regional no resuelve todavía. Se plantea primero identificar el origen de la micropropiedad. ¿Proveía de haciendas como la del Rosario cuyas tierras fueron divididas debido a su endeudamiento y a la aplicación de las leyes de Reforma? ${ }^{42} \mathrm{o}$ ¿eran tierras comunales vendidas a privados, sin que se aplicara allí el recurso del condueñazgo como en otras regiones? El segundo problema consiste, una vez identificadas las categorías pertinentes mediante un microanálisis, en "experimentarlos" en diferentes pueblos de la región, trabajo amplio que requerirá varios años. Finalmente, hemos identificado estrategias por parte de campesinos que descansan, en buena medida, en su capacidad de movilizar en un momento dado sus recursos culturales. El análisis de la construcción social de estos recursos será también un paso necesario para completar esta investigación y proponer así un modelo novedoso de análisis de la Revolución mexicana, construido "a ras del suelo".

42 Autos relativos a la capellanía que reporta la hacienda del Rosario de la Laguna (Tlaxcala). Avalúo de la hacienda. San Martín Texmelucan, 28-I-1850. AHET. Negocios Eclesiásticos, Caja 1, Exp. 58, $196 \mathrm{fs.}$ 1837-1856. 


\section{REFERENCIAS BIBLIOGRÁFICAS}

BARTH, Fredrick

1981 Process and Form in Social Life. London - Boston - Henley. Routledge and Kegan Paul.

BERTRAND, Michel

2011 Grandeza y miseria del oficio. Los oficiales de la Real Hacienda de la Nueva España, siglo XVII y XVIII. [1999] México. FCE - CIDE - CEMCA - Instituto Mora.

Buve, Raymond (ed.)

1984 Haciendas y Central Mexico from Late Colonial Times to the Revolution. Ámsterdam. Centro de Estudios y Documentación Latinoamericanos.

1994 "Movilización campesina y reforma agraria en los valles de Natívitas, Tlaxcala (19171923): estudio de un caso de lucha por recuperar tierras obtenidas durante la revolución armada". En Buve, El movimiento revolucionario en Tlaxcala. México. Universidad Autónoma de Tlaxcala - Universidad Iberoamericana, pp. 151-184.

CAso, Ángel

1950 Derecho agrario. Historia, derecho positivo, antología. México. Porrúa.

Cerutti, Simona

1990 La ville et ses métiers. Naissance d'un langage corporatif (Turin, $17^{e}-18^{e}$ siècle). Paris. EHESS.

2012 Etrangers. Etude d'une condition d'incertitude dans une société d'Ancien Régime. Paris. Bayard.

Crozier, Michel - Friedberg, Erhard

1977 L'acteur et le système. Les contraintes de l'action collective. Paris. Le Seuil.

ELIAS, Norbert

1991 Qu'est-ce que la sociologie? Paris. Editions de l'Aube.

Escobar OHMSTede, Antonio

2008 "El fraccionamiento privado y comunal en el oriente potosino durante la segunda mitad del siglo XIX. Una aproximación”. En Escobar OHMSTede - SÁnchez RodríGuez- Gutiérrez Rivas (coords.), Agua y tierra en México, siglos XIX-XX. México. El Colegio de Michoacán - El Colegio de San Luis, vol. 1, pp. 209-243.

2010 Las estructuras agrarias: pueblos de indios y propiedades privadas. México. Nostra.

ImízCOZ, José María

2010 “Actores, redes, procesos: reflexiones para una historia más global”. Revista da Faculta de Letras, Historia. Porto, III serie, vol. 5, pp. 115-140. [Consulta 2010. Disponible en: http://www.ehu.es/grupoimizcoz.]

Kourí, Emilio H.

2002 "Interpreting the Expropriation of Indian Pueblo Lands in Porfirian Mexico: The Unexamined Legacies of Andrés Molina Enríquez". Hispanic American Historical Review. Durham, vol. 82, nº 1, pp. 69-117.

Leal, Juan Felipe - Menegus, Margarita

1987 "La violencia armada y su impacto en la economía agrícola del Estado de Tlaxcala, 1915-1920". Historia Mexicana. México, no 36:4, pp. 595-642.

2011 Hacendados y campesinos en la revolución mexicana. El caso de Tlaxcala: 19101920. México. Juan Pablos Editor. 
LEVI, Giovanni

1989 Le pouvoir au village. Histoire d'un exorciste dans le Piémont du XVIIème siècle. Paris. Gallimard.

MARichal, Carlos

1994 “La hacienda pública del Estado de México desde la independencia hasta la República Restaurada, 1824-1870". En Marichal - Miño Grijalva -Riguzzi, El primer siglo de la hacienda pública del Estado de México, 1824-1923. México. El Colegio Mexiquense - Gobierno del Estado de México, pp. 101-190.

Nickel, Herbert J.

1987 Relaciones de trabajo en las haciendas de Puebla y Tlaxcala (1740-1914). México. Universidad Iberoamericana.

PeÑAfiel, Antonio

1902 Censo general de la Republica mexicana. Estado de Tlaxcala. México. Secretaría de Fomento.

Ponce Leiva, Pilar - Amadori, Arrigo

2008 "Redes sociales y ejercicio del poder en la América Hispana: consideraciones teóricas y propuestas de análisis". Revista Complutense de Historia de América. Madrid, vol. 34, pp. 15-42.

RAMíREZ RANCAÑO, Mario

1990 El sistema de haciendas en Tlaxcala. México. CONACULTA.

RENDÓN GARCINI, Ricardo

2004 Breve historia de Tlaxcala. México. El Colegio de México - FCE.

ReVEL, Jacques

1989 “L'histoire au ras du sol”. En LeVI, Le pouvoir au village. Histoire d'un exorciste dans le Piémont du XVIIème siècle. Paris. Gallimard, pp. I-XXXIII.

REVEL, Jacques (dir.)

1996 Jeux d'échelles. La micro-analyse à l'expérience. Paris. Gallimard - Le Seuil.

Rosental, Paul-André

1996 “Construire le 'macro' par le 'micro': Fredrik Barth et la microstoria”. En Revel (dir.), Jeux d'échelles. La micro-analyse à l'expérience. Paris. Gallimard - Le Seuil, pp. 141-159.

1999 Les sentiers invisibles. Espace, familles et migrations dans la France du XIXème siècle. Paris. EHESS.

SÁNCHEZ, Evelyne

2011 "Estudio introductorio". En SÁnchez (coord.), Actores locales de la nación en América Latina. Estudios estratégicos. México. BUAP. El Colegio de Tlaxcala, pp. 7-21.

2012 "Santa Apolonia Teacalco (Tlaxcala, México): un pueblo a la conquista de su cabecera en tiempo de revolución". Naveg@mérica. Revista electrónica de la Asociación Española de Americanistas [en línea]. Murcia, no 8, pp. 1-16.

Tortolero, Alejandro

2008 Notarios y agricultores. Crecimiento y atraso en el campo mexicano, 1780-1920. México. UAM - Siglo XXI.

Velasco, Alfonso Luis

1998 Geografía y estadística de Tlaxcala. Versión facsimilar del original publicado en 1892. México. Gobierno del Estado de Tlaxcala. 